\section{EMBRYRIDDLE}

Aeronautical University

SCHOLARLY COMMONS
Journal of Aviation/Aerospace

Education \& Research

Volume 6

Number 1 JAAER Fall 1995

Article 4

Fall 1995

\title{
Should Colleges and Universities Develop Special Alcohol \\ Education and Rehabilitation Programs for Flight Students?
}

Francis X. Goeddeke Jr.

Follow this and additional works at: https://commons.erau.edu/jaaer

\section{Scholarly Commons Citation}

Goeddeke, F. X. (1995). Should Colleges and Universities Develop Special Alcohol Education and Rehabilitation Programs for Flight Students?. Journal of Aviation/Aerospace Education \& Research, 6(1). https://doi.org/10.15394/jaaer.1995.1164

This Article is brought to you for free and open access by the Journals at Scholarly Commons. It has been accepted for inclusion in Journal of Aviation/Aerospace Education \& Research by an authorized administrator of Scholarly Commons. For more information, please contact commons@erau.edu. 


\title{
SHOULD COLLEGES AND UNIVERSITIES DEVELOP SPECIAL ALCOHOL EDUCATION AND REHABILITATION PROGRAMS FOR FLIGHT STUDENTS?
}

\author{
Francis X. Goeddeke Jr.
}

\begin{abstract}
Although the evidence is circumstantial, there are reasons to assume that some college flight students suffer problems relating to excessive alcohol use. Colleges can be more effective in dealing with these problems if the special needs of flight students are considered. Such programs can be as simple as coordinating existing campus alcohol programs as an integrated education, intervention, and medical recertification effort. The goal of any alcohol program would be to provide an environment where flight students can objectively examine their own drinking habits, and have treatment options available if needed.
\end{abstract}

\section{INTRODUCTION}

Alcohol misuse is a problem for college students. Specifically, alcohol use is related to lower grade point averages (Presley \& Meilman, 1992). In one survey (Gadaleto \& Anderson, 1986), college administrators identified alcohol as a factor in $29 \%$ of all cases in which students failed academically, and in $21 \%$ of student attritions. As further demonstration of an alcohol problem, $28 \%$ of college students have reported an alcohol-related memory loss in the past year (Presley \& Meilman, 1992). Heavy alcohol use is correlated with illicit drug use (MacDonald, Barry, \& Fleming, 1992) driving while intoxicated (DWI) convictions (Sarvela, Taylor, Drolet, \& Newcomb, 1988), and alcohol is a significant factor in campus crimes, including rapes (Abbey, 1991). Further, students' drinking-related problems increase after starting college (Gliksman, 1988), and heavy drinking in college is related to heavy drinking later in life (Fillmore, 1975).

Colleges have many reasons for addressing this problem. First, alcohol misuse may reduce student performance and increase student attrition. Second, because most students are still immature, the college may feel a responsibility to help them develop responsible drinking habits. Third, liability problems may arise if colleges are found responsible for alcohol-related crimes or accidents. Colleges generally address the alcohol problem in the following ways: policy, education, and treatment efforts.

College administrators address problems resulting from alcohol use through the development of policies designed to foster responsible use of alcohol. Examples of these policies can be: forbidding the use of alcohol on campus, restricting alcohol use to events where food is served, restricting or eliminating advertising for events or establishments where alcohol is served, requiring that non-alcoholic beverages be available where alcohol is served, and requiring that an event where alcohol is served be registered. Another policy may be to establish alcohol-free housing on campus to support students who wish to remain alcohol-free, whether a student is a recovering alcohol-dependent person or simply because a student chooses to reside in an alcohol-free environment.

Educational efforts may be used to make students more aware of alcohol misuse. These efforts may take the form of articles or notices in school papers, required attendance at orientations, papers, information tables, direct mailings, or alcohol awareness weeks.

Finally, treatment programs may be developed for those who misuse alcohol. Treatment efforts may involve on-campus treatment at a university medical center, or, more frequently, counseling or referral to a community health clinic.

Those pursuing pilot careers have a particular need to know about alcohol misuse. Pilots are prohibited from flying while under the influence of alcohol, with a blood alcohol content (BAC) of at least $0.04 \%$, or within eight hours of consuming alcohol (14 C.F.R. 91.11). Further, a pilot who operates a common carrier under the 
influence of alcohol is subject to a 15-year prison sentence and a $\$ 10,000$ fine (18 U.S.C. 342). A pilot convicted of two alcohol-related motor vehicle convictions (DWIs) in a three-year period may have his or her pilot certificate revoked for up to one year (14 C.F.R. 61.15).

One study (Ross \& Ross, 1990) shows that pilots are largely unaware of the regulations concerning the $0.04 \%$ BAC rule, the amount of alcohol necessary to produce a given $B A C$, and the rate at which $B A C$ decays. This knowledge is important to a pilot, not only to avoid a drinking and flying event, but also because even a single DWI conviction at a young age may be enough to prevent a pilot from getting a job with certain airlines.

The probability of a student pilot using a college aircraft during a drinking and flying event is very low; a student pilot is more likely to engage in a drinking and flying event in an owned or rented aircraft, or in any other type of aircraft after graduation. Although others may not feel remorse for pilots who damage their careers with such an event, the fact remains that with proper education these events can be minimized. Colleges go to great lengths to teach student pilots how to prevent other types of accidents, even providing detailed flight physiology coursework, yet the knowledge that colleges provide student pilots about alcohol may be minimal. Statistically, however, a pilot is much more likely to die from a drinking and flying accident than from any other aeromedical condition.

Another area of concern for pilots is alcohol dependence. In a survey of professional pilots (Ross \& Ross, 1995), respondents felt the major cause of a drinking and flying event would be the pilot's inability to control alcohol use. Apparently, the Federal Aviation Administration (FAA) agrees, and disqualifies pilots with a medical history or with a clinical diagnosis of alcohol dependence from obtaining a required airman medical certificate, unless documented evidence of recovery is presented (14 C.F.R. 67).

A non-diagnostic definition of alcoholism (alcohol dependence), useful to laypersons, is:

a primary, chronic disease with genetic, psychosocial, and environmental factors influencing its development and manifestations. The disease is often progressive and fatal. It is characterized by impaired control over drinking, preoccupation with the drug alcohol, use of alcohol despite adverse consequences, and distortions in thinking, most notably denial. Each of these symptoms may be continuous or periodic. (Morse \& Flavin, 1992)

For the purpose of regulating pilots, the FAA defines alcohol dependence more simply as "a condition in which a person's intake of alcohol is great enough to damage physical health or personal or social functioning, or when alcohol becomes a prerequisite to normal functioning" (14 C.F.R. 67.13).

Left untreated, alcohol dependence is obviously a threat to flying safety. However, admitting and treating alcohol dependence is not always an attractive option for pilots, especially student pilots. Even without the social stigma of lifelong branding as an alcoholic and the loss of a crutch (alcohol), the pilot is likely to lose flying privileges for two years, until the FAA is satisfied the pilot has substantially recovered from alcohol dependence. The threat of the loss of flying privileges for two years is obviously an unpleasant thought to a student pilot who looks forward to an aviation career, especially a student who may have already invested a substantial amount of time and money in pursuing an aviation degree and pilot certificates. However, in the airlines and commercial aviation, a solution to this motivational problem has been developed, one that could be adapted for college and university flight schools.

From 1960 to 1971, eight airline transport pilots with a diagnosis of alcohol dependence petitioned the FAA for a medical certificate. All eight were denied (Federal Aviation Administration, 1976). The Air Line Pilots Association (ALPA) realized there was a problem here. If a pilot was alcohol-dependent and did not seek treatment, the pilot was a threat to safety and the professional image of the industry. However, if a pilot did seek treatment for alcohol dependence, the pilot's career was terminated.

\section{ALPA HIMS PROGRAM}

In 1974, ALPA received a grant from the National Institute of Alcohol Abuse and Alcoholism to develop a model program for the early detection and prevention, facilitation of intervention, treatment, and rehabilitation 
of alcohol-dependent pilots (Masters, Hoover, Hutchings, Gilstrap, Chase, \& Pickersgill, undated). This program was named Human Intervention and Motivational Study (HIMS).

The HIMS program is based on educational efforts, peer intervention, impartial evaluation, alcoholism treatment, continuing therapy, medical recertification, and return to duty. All pilots in a company participate in educational efforts on alcohol dependence during initial and recurrent training sessions. Pilots learn about the symptoms and treatment of alcohol dependence, as well as details about their employee assistance and medical recertification programs. One of the main reasons for the success of the HIMS program is peer intervention, in which a pilot's own peers, out of concern for the pilot, intervene and report cases of suspected alcohol misuse to an intervention team. The intervention team is composed of peer, union, and company representatives, and has been trained to investigate suspected alcohol abuse by pilots. Once the team investigates a pilot, a determination is made on whether to intervene. If an intervention is warranted, the team coordinates efforts by the pilot's peers and perhaps family members to confront the pilot with specific instances of behavior that indicate an alcohol problem. The pilot is urged to voluntarily seek an impartial medical substance abuse evaluation.

If that evaluation finds the pilot is alcoholdependent, the pilot will usually attend a 28-day inpatient treatment program, usually followed with a "90-90," or 90 Alcoholics Anonymous (AA) meetings in a 90-day period. Attendance at Birds of a Feather, an organization of pilots in AA, is also encouraged. Outpatient alcohol dependence counseling is continued with a therapist. Each pilot may have unique treatment needs. During this time, the pilot obtains a medical sponsor, an FAA Aviation Medical Examiner who is specially qualified to handle alcohol dependence cases. The medical sponsor is kept up to date on the pilot's progress, and when the sponsor feels the pilot has shown enough evidence of recovery for a medical certificate, the sponsor helps the pilot gather and present the information to the FAA in a way that is beneficial to the pilot.

If the FAA grants the pilot a medical certificate, it is granted on the condition of sustained total abstinence from alcohol. Once the certificate is granted, the FAA requires monthly follow-up reports from the pilot's medical sponsor, and from union and company representatives. The pilot is aware that any time the medical sponsor, union or company representative, or the FAA is not satisfied with the pilot's progress, the medical certificate may be revoked immediately. This circumstance usually provides enough motivation for the pilot to maintain an exemplary recovery program. Because of this monitoring procedure, the FAA may grant a medical certificate to an alcohol-dependent pilot after only several months of abstinence, rather than after the standard two years.

After at least two years of abstinence from alcohol and with the recommendation of the medical sponsor, the FAA may discontinue the requirement for further monitoring and follow-up reports. However, the pilot is still required to remain totally abstinent from alcohol for continued medical certification.

The HIMS program has been very successful. In 1993, first-class medical certificate holders, most of whom have access to the HIMS program, were 19 times more likely to be admitted, recovered alcohol-dependent individuals than third-class medical certificate holders, most of whom do not have access to the HIMS program. Since the airlines implemented the HIMS program, more than 1,500 pilots have recovered from alcoholism, with a recovery rate, as determined by a two-year abstention from alcohol, approaching 94\% (Federal Air Surgeon, 1995). Most of these pilots would probably have continued their excessive drinking, while continuing their flying careers, if it were not for this rehabilitation program.

\section{ADAPTING HIMS \\ TO THE COLLEGE ENVIRONMENT}

It is not hard to imagine a similar alcohol program for college flight students. The first component would be required education programs for flight students, detailing the regulations on alcohol use for pilots, the calculation of blood alcohol levels, the nature of alcohol dependence, and the counseling, treatment, and medical recertification options available for alcohol dependence at the school and after graduation. Logically, it appears that presenting this material in a flight physiology course would be 
appropriate, but this information may best be presented to the student as soon as flight training begins. For example, one of the goals of the educational program would be to help reduce the frequency of DWIs among flight students. A DWI conviction will be just as harmful to the student's record whether the DWI conviction occurs during the first or the last semester of the student's college career. Thus, this alcohol education material should be presented at the beginning of flight training, not semesters or years into it. Also, several follow-up alcohol education sessions should be required throughout the rest of each student's college career, perhaps integrated into existing flight courses.

The second component would be to establish the framework for medical recertification after treatment. Although this is not being done currently in the academic environment, with the tight regulation of flying at a college, a monitoring program similar to the airline monitoring program could be submitted to the FAA for evaluation. The opportunity to become medically recertified in as short a time as possible is critical in the college environment, where alcohol dependence evaluation and treatment are voluntary. All counselors in the counseling department must become familiar with the medical recertification questions a student pilot may have. A specially trained FAA Aviation Medical Examiner who is qualified to act as a medical sponsor would be required, either as a consultant or on the college staff. That person can help arrange a suitable monitoring team, which might consist of the chief pilot or some other flight department official, a substance abuse counselor in the counseling department, and perhaps volunteer student peer(s). ALPA, under a grant from the FAA, provides annual training for those who are part of the monitoring process.

An alcohol rehabilitation program for college students may not be as successful as the program in the airlines, in part because of the population differences in age, and in part because the airlines are able to use intervention and leverage techniques that would be inappropriate in the college environment. Nevertheless, alcohol problems abound among the college-age population, and limited use of intervention and leverage may be acceptable in a college environment.

\section{CURRENT ALCOHOL APPROACHES IN COLLEGES}

Intervention efforts are not entirely new to the college environment. One non-flight college (Cronin, 1991) successfully uses an intervention strategy to encourage students to voluntarily seek alcohol treatment. A referral to the counseling department is usually initiated as the result of an alcohol-related disciplinary incident, such as violations of residence hall alcohol policy. Referrals also are initiated by other staff and students. Those making referrals may request that they not be identified to the referred student. A form letter is sent to the student who has been referred to the counseling center, requesting that the student make an appointment with the counseling center. Most of the students, though under no obligation to do so, make an appointment within one week. Counselors talk with the individual, develop a rapport, and offer the student an opportunity to select and complete one of several paperand-pencil alcohol dependence screening tests. Preliminary findings suggest that $65 \%$ of students whose screening test scores suggest an alcohol problem make a follow-up counseling appointment.

The use of leverage also is not new to the college environment (Meilman, 1992). Meilman cites two cases in which students made requests to drop classes for medical reasons (alcohol-related), also in a non-flight college. One student was told that after attending weekly counseling and six Alcoholics Anonymous meetings for the remaining five weeks of the term, he would be allowed to drop the course for medical reasons. The student fulfilled his obligation, and the school honored its promise. The other student was similarly told to attend counseling sessions and Alcoholics Anonymous, but was granted the course drop immediately. Consequently, the student lacked motivation to follow through with his obligation and, two years later, still had an alcohol problem.

\section{CONCLUSION}

Why should a college go through all the trouble to develop a special alcohol program for flight students? First, it seems reasonable to assume the alcohol problem exists in colleges, and pilots do have special needs in the area of alcohol misuse. An alcohol program for flight students may reduce attrition, improve academic 
performance, help prevent a damaging episode to a student's flying career, and decrease the probability of an alcohol-related accident. Also, as it now stands, a student pilot aware of the medical recertification procedures for alcohol dependence may already be recertified, without the school's knowledge. It may be better for the school to help the pilot be recertified, rather than encouraging the student to hide alcohol rehabilitation from the school. Replacing a drinking alcohol-dependent pilot in the student pilot population with a non-drinking alcoholdependent student pilot may help to marginally change that group's attitudes toward alcohol misuse for the better. Finally, the school may already have an employee assistance plan for its employees, and flight instructors who might participate in that plan may also need a medical and operational monitoring program for their continued medical certification, which might also be extended to them.

It would be hard to evaluate the success of an alcohol program based solely on the number of students who seek treatment and recertification assistance from the school. Rather, the real success of the program would be in how well the school provides an environment where students are encouraged to intelligently and objectively examine their own drinking habits. This open and objective awareness of alcohol problems can then be car- ried with the pilots throughout their flying careers.

But what of the negative public image of knowing that alcohol-dependent students are flying at a given college? Perhaps there would be a negative image among the ill-informed. However, the problem of alcohol misuse in aviation is not going to go away by itself, and proactive approaches like those suggested here are necessary to help solve the problem. Hopefully, the positive image these ideas may promote among the enlightened may outweigh the negative image among the ignorant. Indeed, airlines have had to face such a negative image. The bottom line is that the flying public is much safer these days with alcohol rehabilitation programs in the airlines than they were without them.

Northwest Airlines faced a dilemma in the decision to rehire a former captain who was fired for flying a 727 with passengers while under the influence of alcohol ("Airline Gives," 1993). After the event, the pilot underwent treatment for alcohol dependence and served his prison sentence. Eventually, Northwest rehired the former captain as a ground instructor. The rehiring was meant to send a message to other Northwest employees that if they want to get help for an alcohol problem, the company will stand behind them. Flight students likewise need someone to stand up for them if they want to get help for an alcohol problem.

Francis X. Goeddeke Jr. earned a Master of Aeronautical Science degree in Human Factors and a Bachelor of Science degree in Professional Aeronautics, both from Embry-Riddle Aeronautical University.

\section{REFERENCES}

Abbey, A. (1991). Acquaintance rape and alcohol consumption on college campuses: How are they linked? Journal of American College Health, 39(4), 165-169.

Cronin, C. (1991). A technique for overcoming denial in problem drinking students. Journal of College Student Psychotherapy, 6(1), 75-83.

Federal Air Surgeon. (1995, April 10). Presentation at the Sun 'n Fun fly-in, Lakeland, FL.

Federal Aviation Administration. (1976). Alcoholism and airline flight crewmembers. Policy letter. Washington, DC: Department of Transportation.

Fillmore, K. M. (1975). Relationships between specific drinking problems in early adulthood and middle age. Journal of Studies on Alcohol, 36(7), 882-907.

Gadaleto, A. F., and Anderson, D. S. (1986). Continued progress: The 1979, 1982, and 1985 college alcohol surveys. 
Journal of College Student Personnel, 27(6), 499-509.

Gliksman, L. (1988). Consequences of alcohol use: Behavior changes and problems during first year of university. The International Journal of the Addictions, 23(12), 1281-1295.

MacDonald, R., Barry, K. L., and Fleming, M. F. (1992). Patterns of substance use among students meeting lifetime DSM-III criteria for alcohol misuse. The International Journal of the Addictions, 27(8), 905-915.

Masters, R. L., Hoover, E. P., Hutchings, C. L., Gilstrap, R. W., Chase, G. S., and Pickersgill, J. A. (undated). An occupational alcoholism program for professional airline pilots: A preliminary report. NIAAA Grant Number 1 R18 AA01484. Denver, CO: Air Line Pilots Association.

Meilman, P. W. (1992). Alcohol education and treatment: On the use of leverage in the college setting. Journal of American College Health, 11(2), 79-81.

Morse, R. M., and Flavin, D. K. (1992). The definition of alcoholism. The Journal of the American Medical Association, $268,1012-1013$.

Airline gives ex-drunken pilot a second chance. (1993, October 14). New York Times, p. B9.

Presley, C. A., and Meilman, P. W. (1992). Alcohol and drugs on American college campuses: A report of college presidents. Carbondale, IL: Student Health Program Wellness Center, Southern Illinois University.

Ross, S. M., and Ross, L. E. (1990). Pilots' knowledge of blood alcohol levels and the $0.04 \%$ blood alcohol concentration rule. Aviation, Space, and Environmental Medicine, 61, 412-417.

Ross, S. M., and Ross, L. E. (1995). Professional pilots' views of alcohol use in aviation and the effectiveness of employee assistance programs. The International Journal of Aviation Psychology, 5(2), 199-214.

Sarvela, P. D., Taylor, E. L., Drolet, J. C., and Newcomb, P. R. (1988). Indicators of drinking and driving among university students. Health Education, 19(5), 72-77. 